\title{
Sintetizando los resultados de los estudios sobre el fenómeno de las drogas
}

\author{
Antonia Regina Ferreira Furegato
}

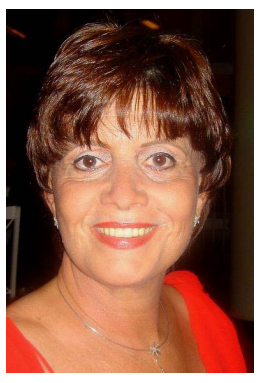

Las investigaciones que fueron sido realizadas por los profesionales, directa o indirectamente, relacionados al área de la salud, a través del CICAD (Programa de Capacitación en Investigación en América Latina), traen importantes resultados que podrán contribuir para las prácticas así como para la enseñanza pero, principalmente, para los formuladores de políticas de combate al uso y al abuso del alcohol y otras drogas.

En los estudios multicéntricos realizados por investigadores de varios países latino-americanos y de Canadá, entre jóvenes adultos que se identificaron personalmente como afectados por la droga ${ }^{(1)}$, los informantes reconocen que: los familiares y los gobernantes son los principales responsables por la prevención del problema de las drogas; que las leyes vigentes ejercen una influencia negativa, especialmente en los usuarios, necesitándose de una revisión crítica de sus objetivos y alcance; y, que las leyes son poco punitivas y no alcanzan al comportamiento criminal de los consumidores y traficantes. También, reconocen que existe una aplicación equivocada de la legislación y de las políticas públicas en el usuario de drogas por el Sistema Único de Salud-SUS. Tanto el estigma como las opciones insuficientes de tratamiento y las dificultades de acceso a los servicios fueron apuntadas como barreras para el enfrentamiento del problema. En los servicios de salud de los diferentes países se percibe la ausencia de medidas terapéuticas y preventivas claramente formuladas e implementadas.

Los sujetos mencionan que las iglesias y otras instituciones religiosas han incluido entre sus preocupaciones el asunto de las drogas, adentrándose en ese contexto para buscar soluciones.

También, se observa, en estos estudios, que cuidadores o personas que se importan con los usuarios de drogas son, en general, mujeres que aceptan esta responsabilidad en las familias afectadas, inclusive sin contar con el debido apoyo y orientación.

Señalan, también, que hay necesidad de ofrecer un retorno concreto y objetivo de los resultados de las investigaciones y de las acciones implementadas en el área de la salud y de las diversas instancias del saber y de los poderes.

Algunos investigadores de diferentes países latinoamericanos hicieron importantes contribuciones sobre lo que es considerado factor de riesgo y factores protectores para la población joven en su contacto con el alcohol, el tabaco y otras drogas ${ }^{(2-3)}$.

Como factores personales, sociales y comunitarios de riesgo pueden ser citados: - edad, baja autoestima, soledad, inseguridad; - curiosidad y atracción por las experiencias nuevas y desafiantes; - experiencia anterior con tabaco y alcohol; - presión de los amigos que usan drogas; - feminización del consumo y del tráfico; - inseguridad sobre el futuro; - problemas familiares (conflictos, violencia, falta de comunicación, rechazo); - presencia de evento estresante; - falta de conocimiento y de comprensión sobre las consecuencias perjudiciales del uso y del abuso del alcohol, del tabaco y de otras drogas; - inadecuada respuesta social para el enfrentamiento de problemas.

El ingreso en la Universidad es un factor de crecimiento y valorización personal del joven, sin embargo, favorece la exposición a múltiples factores de riesgo por las nuevas demandas y desafíos.

Como factores protectores, los sujetos participantes de estas investigaciones señalan: - Familias que invierten en el acompañamiento muy próximo de cada movimiento de sus hijos, vigilando su transición hacia la madurez 
durante la adolescencia e el ingreso en la vida adulta. - Interés de los familiares y el afecto demostrados en lo cotidiano son importantes elementos para el desarrollo emocional de los hijos. - Presencia de normas claras y objetivas, así como flexibilidad y comunicación abierta pueden ayudar al joven y a sus familiares. - Programas de prevención en el medio universitario, con oferta de actividades deportivas, recreativas y culturales, además de las académicas formales.

Resultados de estudios sobre percepción del consumo por los pares universitarios mostraron que el consumo es sobreestimado, o sea, los jóvenes, especialmente los del sexo femenino, creen que el consumo entre sus pares es más alto que lo ocurre en la realidad. La percepción sobreestimada, principalmente en relación al tabaco, a la mariguana y a la cocaína así como la percepción subestimada en relación al alcohol tiene influencia en la decisión del joven sobre su uso(4).

En esta edición de la Revista Latinoamericana de Enfermería se reúnen diversas contribuciones de las investigaciones realizadas, a través del Programa Internacional de Capacitación en Investigación para Profesionales de la Salud-CICAD para enfrentamiento del problema de las drogas, por investigadores de Brasil, Ecuador, Bolivia, Perú, México, Colombia, Costa Rica, Argentina, Nicaragua y Cabo Verde.

Las contribuciones enfocan a la enfermería y a otras profesiones del área de la salud con sus conceptos, prejuicios, conocimientos y opiniones sobre tabaco, alcohol y otras drogas. Se presentan también resultados de otros estudios realizados entre jóvenes, familiares y profesionales del área de la salud sobre tabaco, alcohol y otras drogas, así como las consecuencias de su uso o abuso. Hay también, en este número, estudios sobre conceptos y actitudes sobre drogas en la infancia, en la adolescencia y entre la población femenina así como el familiar/cuidador del usuario de drogas. Las investigaciones avanzaron también en el sentido de las consecuencias concretas resultantes del uso y del abuso con las drogas tales como accidentes de tránsito, violencia doméstica y otras.

Actualmente, varias acciones han sido emprendidas internacionalmente; en Brasil fueron medidas de control y prevención y, programas con apoyo de las acciones para políticas públicas. Los ministerios de Educación, Salud y Justicia brasileños establecieron algunas líneas divisorias en la organización y se propusieron avanzar de forma interconectada para hacer frente al problema. Fue creada la Secretaría Nacional Antidrogas (SENAD) y diversos órganos están adoptando el modelo geopolítico estructural para el control del tráfico y uno está adoptando el modelo biomédico para lidiar con el fenómeno como una enfermedad psicobiológica. También, se creó una red de investigaciones sobre drogas, optimizando los recursos disponibles. La legislación, en vigor desde 2006, no contempla apenas el aspecto legal, ella también incluye los aspectos terapéuticos(5).

Así siendo, se espera que las informaciones extraídas de las investigaciones realizadas en los diferentes países latinoamericanos y en Canadá ayuden a: - ajustar los programas preventivos; - dirigir la divulgación de estas cuestiones en los medios de comunicación; - definir normas y políticas de prevención y enfrentamiento del problema; y, - favorecer las acciones terapéuticas y de rehabilitación para aquellas personas y familias afectadas por el uso y por el abuso de alcohol, tabaco y otras drogas. Se espera también que los jóvenes sean instruidos en lo que se refiere a los efectos nocivos de esas drogas y sobre los recursos que disponen en caso de precisar de ayuda. Se espera que los profesionales que actúan en los diferentes servicios de la salud tengan más elementos y técnicas para instrumentalizar sus prácticas.

\section{Referencias}

1. Silva J, Ventura CAA, Vargens OMC, Loyola CMD, Eslava Albarracín DG, Diaz J, et al. Illicit drug use in seven latinamerican countries: critical perspectives of families and familiars. Rev. Latino-Am. Enfermagem. 2009;17(Esp.):763-9.

2. Rodríguez Funes GM, Brands B, Adlaf E, Giesbrecht N, Simich L, Wright MGM. Factores de riesgo relacionados al uso de drogas ilegales: perspectiva crítica de familiares y personas cercanas en un centro de salud público en San Pedro Sula, Honduras. Rev. LatinoAm. Enfermagem. 2009; 17(Esp.):796-802.

3. Oviedo Rodriguez RJ, Brands B, Adlaf E, Gierbrecht N Simich L, Wright MGM. Factores de protección relacionado al uso de drogas ilícitas: perspectiva crítica de familiares y personas cercanas la los usuarios de drogas, en la Ciudad de Guayaquil, Ecuador. Rev. Latino-Am. Enfermagem 2009; 17(Esp.): 831-837.

4. Bustamante IV, Carvalho AMP, Oliveira EB, Oliveira Júnior HP, Santos Figueroa SD, Montoya Vásquez EM, et al. Normas percebidas por estudantes universitários sobre seus companheiros y uso de drogas: um estudio multicentrico en cinco países de la América Latina. Rev. Latino-Am. Enfermagem 2009; 17(Esp.): 838-843.

5. Ventura CAA, Brands B, Adlaf E, Giesbrecht N, Simich L, Wright MGM, Ferreira OS. Políticas y leis sobre drogas ilícitas en el Brasil y la perspectiva de familiares y pesoas próximas la usuários de drogas: estudio en la cidade de Ribeirão Preto, São Paulo, Brasil. Rev Latino-am Enfermagem 2009 novembro-dezembro; 17(Esp.):810-6.

Antonia Regina Ferreira Furegato es miembro de la Comisión Editorial de la Revista Latino-Americana de Enfermagem, y Profesor Titular de la Escuela de Enfermería de Ribeirão Preto de la Universidad de São Paulo, Centro Colaborador de la OMS para el Desarrollo de la Investigación en Enfermería, SP, Brasil, e-mail: furegato@eerp.usp.br. 